\title{
Test of Natural Potential Method in Locating Cave Passageways of Jewel Cave
}

\author{
Arthur L. LANGE \\ ThE GEOPHYSICS Group \\ WHEATRIDGE, CO
}

Ever increasing pressures on our natural environment necessitate measures to detect and ameliorate problems of contamination, construction and overuse, before they become critical. This is particularly the case in our national parks and monuments where the tide of visitors is continually growing. the underground resource of natural caverns is especially vulnerable to damage, due to its fragile features, rare and delicate biota, open communication with groundwater, and its invisibility beneath the ground surface. It is important that we be able to recognize the existence of a cavern system prior to the planning of roads and facilities that may encroach upon or introduce waste and hazardous materials into the underground system.

To minimize the effect of surface development and construction on the subterranean system of Jewel Cave National Monument, South Dakota, it is necessary to detect and map the caverns from the surface beyond the known $130 \mathrm{~km}$-extent mapped by explorers. Because of its limited passage size and depth (ranging between 30 an $120 \mathrm{~m}$ ), and the area's high surface relief, resolution of underground galleries by active electrical, seismic and gravity methods would be time-consuming, expensive, and possibly unavailing.

A number of geophysical tools have been applied to the detection and mapping of caves and tunnels, including gravity, seismic and active electrical methods. In the case of voids at depths of 50 or more meters and of limited dimensions, particularly in areas of considerable relief, these methods lose resolving power; furthermore, they become costly to implement. As a practical alternative, the natural-potential method offers a rapid and economical technique whose response is based on the movement of groundwater not only at cave-depth but within the zone of infiltration between the cave and the surface. Although the natural-potential has been applied for many years in the exploration for minerals and for targeting dam leakage, its application to cave mapping has been undertaken only recently. Tests over caverns in Kentucky, Missouri, Texas and Nevada have demonstrated its efficacy for detecting voids and underground streams at depths between the surface and forty or more meters.

Jewel Cave is a deep (30-140 m) and comp. $\mathrm{x}$ network of galleries and tubes in Madison limestone, lacking voids of a size readily targeted by other geophysical methods. The local relief exceeds $150 \mathrm{~m}$, and for the most part is covered by forest. All in all, it is an ideal area for testing the capability of the naturalpotential method. Four trial lines were laid out, totaling $2.9 \mathrm{k}$ in length, to cross over portions of the mapped cavern representing both relatively simple as well as complex cave structure. The flagging and data acquisition on these four lines were completed by the two-person crew in three days. 
The natural-potential profiles revealed a direct correlation of negative anomalies with mapped caverns at a variety of depths, as expected in a carbonate environment containing waters of $\mathrm{pH}>7$, as is the case at Jewel Cave. Of the $825 \mathrm{~m}$ of mapped cave crossed by the profiles only one $60 \mathrm{~m}$ segment of cavern, exceeding $50 \mathrm{~m}$ in depth showed no evident potential low (possibly the effect of mis-location). Thus, in relative terms, $93 \%$ of the known cavern system crossed by the profiles produced a definitive response. No relationship between millivolt response and elevation or lithology was evident in the plots.

An additional $500 \mathrm{~m}$ of relatively negative response appeared in the profiles, of which $200 \mathrm{~m}$ occurred over meadow and $150 \mathrm{~m}$ over fault zones, where in both cases, enhanced infiltration may be expected. These are also possible zones for cavern development beyond the mapped extent of the cave system.

In conclusion, the natural potential method delineated approximately $93 \%$ of the mapped cavern crossed over by the survey lines, and indicated additional zones of likely uncharted cavern. It mapped clearly the cone of depression around a pumping well and the main east/west fault crossing the Monument. The method can be relied upon for detecting and mapping undiscovered cavern in the Jewel Cave environment, with possible follow-up confirmation over selected areas of concern by precise gravimetric observations. 